\title{
Temperature-induced changes in egg white antimicrobial concentrations during pre-incubation do not influence bacterial trans-shell penetration but do affect hatchling phenotype in Mallards
}

\author{
Jana Svobodová $^{1}$, Jakub Kreisinger ${ }^{2}$, Veronika Gvoždíková Javůrková ${ }^{\text {Corresp. } 3,4}$ \\ 1 Faculty of Environmental Sciences, Department of Ecology, Czech University of Life Sciences, Prague 6, Suchdol, Czech Republic \\ 2 Faculty of Science, Department of Zoology, Charles University Prague, Prague 2, Czech Republic \\ 3 Institute of Vertebrate Biology, Czech Academy of Sciences, Brno, Czech Republic \\ 4 Faculty of Agrobiology, Food and Natural Resources, Department of Animal Science, Czech University of Life Sciences, Prague 6, Suchdol, Czech \\ Republic \\ Corresponding Author: Veronika Gvoždíková Javůrková \\ Email address: veronika.javurkova@gmail.com
}

Microbiome formation and assemblage are essential processes influencing proper embryonal and early-life development in neonates. In birds, transmission of microbes from the outer environment into the egg's interior has been found to shape embryo viability and hatchling phenotype. However, microbial transmission may be affected by egg-white antimicrobial proteins (AMPs), whose concentration and antimicrobial action are temperature-modulated. As both partial incubation and clutch covering with nest-lining feathers during the pre-incubation period can significantly alter temperature conditions acting on eggs, we experimentally investigated the effects of these behavioural mechanisms on concentrations of both the primary and most abundant egg-white AMPs (lysozyme and avidin) using mallard (Anas platyrhychos) eggs. In addition, we assessed whether concentrations of egg-white AMPs altered the probability and intensity of bacterial trans-shell penetration, thereby affecting hatchling morphological traits in vivo. We observed higher concentrations of lysozyme in partially incubated eggs. Clutch covering with nest-lining feathers had no effect on egg-white AMP concentration and we observed no association between concentration of egg-white lysozyme and avidin with either the probability or intensity of bacterial trans-shell penetration. The higher egg-white lysozyme concentration was associated with decreased scaled body mass index of hatchlings. These outcomes demonstrate that incubation prior to clutch completion in precocial birds can alter concentrations of particular egg-white AMPs, though with no effect on bacterial transmission into the egg in vivo. Furthermore, a higher egg white lysozyme concentration compromised hatchling body condition, suggesting a potential growth-regulating role of 


\section{Temperature-induced changes in egg white}

\section{2 antimicrobial concentrations during pre-incubation do}

3 not influence bacterial trans-shell penetration but do

4 affect hatchling phenotype in Mallards

6 Jana Svobodová ${ }^{1}$, Jakub Kreisinger 2, Veronika Gvoždíková Javůrková ${ }^{3,4}$ *

7

$8{ }^{1}$ Czech University of Life Sciences, Faculty of Environmental Sciences, Department of Ecology,

9 Kamýcká 1176, 16500 Prague 6, Czech Republic

$10{ }^{2}$ Charles University, Faculty of Science, Department of Zoology, Viničná 7, 12844 Prague 2,

11 Czech Republic

$12{ }^{3}$ Institute of Vertebrate Biology, Czech Academy of Sciences, Květná 8, 60365 Brno, Czech

13 Republic

$14{ }^{4}$ Czech University of Life Sciences, Faculty of Agrobiology, Food and Natural Resources,

15 Department of Animal Science, Kamýcká 957, 16500 Prague 6, Czech Republic

17 Corresponding Author*:

Veronika Gvoždíková Javůrková *

Institute of Vertebrate Biology, Czech Academy of Sciences, Květná 8, 60365 Brno, Czech

Republic

Czech University of Life Sciences, Faculty of Agrobiology, Food and Natural Resources, 


\section{Abstract}

Microbiome formation and assemblage are essential processes influencing proper embryonal and early-life development in neonates. In birds, transmission of microbes from the outer environment into the egg's interior has been found to shape embryo viability and hatchling phenotype. However, microbial transmission may be affected by egg-white antimicrobial proteins (AMPs), whose concentration and antimicrobial action are temperature-modulated. As both partial incubation and clutch covering with nest-lining feathers during the pre-incubation period can significantly alter temperature conditions acting on eggs, we experimentally investigated the effects of these behavioural mechanisms on concentrations of both the primary and most abundant egg-white AMPs (lysozyme and avidin) using mallard (Anas platyrhychos) eggs. In addition, we assessed whether concentrations of egg-white AMPs altered the probability and intensity of bacterial trans-shell penetration, thereby affecting hatchling morphological traits in vivo. We observed higher concentrations of lysozyme in partially incubated eggs. Clutch covering with nest-lining feathers had no effect on egg-white AMP concentration and we observed no association between concentration of egg-white lysozyme and avidin with either the probability or intensity of bacterial trans-shell penetration. The higher egg-white lysozyme concentration was associated with decreased scaled body mass index of hatchlings. These outcomes demonstrate that incubation prior to clutch completion in precocial birds can alter concentrations of particular egg-white AMPs, though with no effect on bacterial transmission into the egg in vivo. Furthermore, a higher egg white lysozyme concentration compromised hatchling body condition, suggesting a potential growth-regulating role of lysozyme during embryogenesis in precocial birds. 
50 Host-microbiome interactions and assemblage during embryonal and early-life phases appear

51 to be strong determinants of the prosperity and overall success of progeny (Calatayud et al.

52 2019; Campos-Cerda \& Bohannon 2020; Chen et al. 2020; Osorio 2020; Voirol et al. 2020).

53 Avian eggshell microbiomes are diverse (Grizard et al. 2014; van Veelen et al. 2018) and are

54 primarily shaped by the nest material, the local environment and the parent's skin and feathers

55 (Diaz-Lora et al. 2019; Martinez-Garcia et al. 2016; Ruiz-Castellano et al. 2016; van Veelen et

56 al. 2017). As documented under both natural (Cook et al. 2003) and experimental conditions

57 (Javůrková et al. 2014; Wang et al. 2018), these eggshell microorganisms are capable of

58 entering avian egg content, a process known as microbial trans-shell penetration. Unlike the

59 broadly documented associations between eggshell microbiota and hatching success (e.g. Lee

60 et al. 2017; Peralta-Sanchez et al. 2018), studies investigating proximate effects of penetrating

61 microorganisms on avian embryos and hatchlings are scarce, with the few published reports to

62 date documenting suppressed embryo viability (Cook et al. 2005a; Cook et al. 2003; Cook et al.

63 2005b; Wang et al. 2011) or decreased residual body weight of hatchlings (Javůrková et al.

64 2014).

65 Birds have evolved numerous egg-related and behavioural mechanisms to protect

66 against uncontrolled proliferation of microbes outside and inside the egg. Eggshell pigmentation

67 (Ishikawa et al. 2010), eggshell microstructure characteristics (D'Alba et al. 2017; Grellet-Tinner

68 et al. 2017; Martin-Vivaldi et al. 2014), cuticle nanostructuring (D'Alba et al. 2014), deposition of

69 antimicrobial proteins into eggshell structures (Bain et al. 2013; Gautron et al. 2011; Wellman-

70 Labadie et al. 2008a) and nest material (Diaz-Lora et al. 2019; Ruiz-Castellano et al. 2019;

71 Ruiz-Castellano et al. 2016) have all been found to significantly shape eggshell microbiota. In

72 comparison, mechanisms reducing microbial trans-shell penetration and proliferation of

73 microbes inside the egg have primarily been linked with egg incubation (Fang et al. 2012a;

74 Svobodová et al. 2019) and the concentration of miscellaneous egg-white proteins (Mann \& 
75 Mann 2011; Sun et al. 2017), especially those having antimicrobial potential (Baron \& Jan 2011;

76 Svobodová et al. 2019; Wellman-Labadie et al. 2008b).

77 Among the most abundant, and most investigated, egg-white antimicrobial proteins

78 (AMPs) are lysozyme, ovotransferrin and avidin (Ibrahim 2019; Sun et al. 2017). While

79 lysozyme shows strong bactericidal activity against both G+ and G- bacteria (Ibrahim et al.

80 2001; Wellman-Labadie et al. 2008b), avidin and ovotransferrin are more bacteriostatic (Guyot

81 et al. 2016a; Guyot et al. 2016b; Wellman-Labadie et al. 2008b) due to their ability to reversibly

82 bind biotin and iron, thus making them unavailable for bacterial growth (Board \& Fuller 1974;

83 Pierce et al. 2021; Wu \& Acero-Lopez 2012). Owing to their broad antimicrobial potential, most

84 egg-white AMPs are considered as essential maternal effects transferred into the egg in birds

85 (Bonisoli-Alquati et al. 2010; Saino et al. 2007). For example, higher egg-white lysozyme

86 concentration was found in eggs produced after mating with a better quality male (Saino et al.

87 2007), or to be associated with improved hatchability and innate immunity of hatchlings (Saino

88 et al. 2002). Egg-white proteomic profiles may change significantly during the incubation cycle,

89 however, with increases in the concentration and relative abundance of egg-white AMPs due to

90 the water loss (Guyot et al. 2016b), phosphorylation, glycosylation or decreased solid albumin

91 (Zhu et al. 2019), and decreases in concentration due to the formation of protein complexes

92 and/or protein aggregations (Liu et al. 2015; Qiu et al. 2012) during the first 12 days of

93 incubation, all of which may lead to alterations in egg-white antimicrobial potential (Fang et al.

94 2012a; Fang et al. 2012b; Grizard et al. 2015). Further, the different incubation patterns of

95 altricial and precocial birds have been shown to result in temperature-induced changes in egg-

96 white lysozyme and ovotransferrin concentration, enhancing the proliferation of beneficial

97 probiotic microorganisms in the egg-white (Svobodová et al. 2019). It is likely, therefore, that

98 while incubation may significantly shift eggshell microbiota (Bollinger et al. 2018; Grizard et al.

99 2014; Grizard et al. 2015; Ruiz-De-Castaneda et al. 2011; Ruiz-de-Castaneda et al. 2012), its

100 selective antimicrobial effect inside the egg is most probably inherent in mediation of changes in 
101 the egg-white chemical and proteomic profile, where an increase/decrease in lysozyme and

102 avidin would be expected. Furthermore, as evidence exists for a physiological role of lysozyme

103 and avidin on the developing embryo, resulting in alterations of body morphological traits of

104 hatchlings (Javůrková et al. 2015; Krkavcová et al. 2018), incubation-mediated changes in egg-

105 white AMP concentration may also significantly shape the hatchling's morphology. To date,

106 however, experimental evidence for the interactive effects of egg-white AMP profile and

107 incubation under natural conditions are lacking.

108 Another behavioural mechanism with the potential to reduce risks of microbial trans-shell

109 penetration is clutch covering with nest-lining material during the pre-incubation period. Recent

110 studies suggest that the nest material and nest-lining feathers most likely affect the eggshell

111 microbial assemblage via antimicrobial agents produced by microorganisms in the preen gland

112 (Diaz-Lora et al. 2019; Ruiz-Castellano et al. 2019; Ruiz-Castellano et al. 2016). In addition to

113 the direct antimicrobial action of nest-lining feathers, clutch covering protects the exposed clutch

114 against ambient temperature fluctuations during the pre-incubation period (Pinowski et al. 2006;

115 Prokop \& Trnka 2011). While clutch covering with nest-lining material appeared to have no

116 effect on bacterial trans-shell penetration in a previous experimental study (Javůrková et al.

117 2014), it may affect the temperature acting on exposed eggs, thereby inducing temperature-

118 mediated changes in egg-white AMP concentration. To date, however, the proximate role of

119 clutch covering with nest-lining feathers on egg-white AMP concentration has not yet been

120 evaluated.

121 In this study, we experimentally test whether partial incubation and clutch covering with

122 nest-lining feathers during pre-incubation affects concentrations of the two principle egg-white

123 AMPs, lysozyme and avidin, using precocial mallard eggs exposed in their natural breeding

124 habitat. Partial incubation, a behaviour preceding full incubation of the complete clutch observed

125 in many bird species (Wang \& Beissinger 2011), keeps the eggs dry (D’Alba et al. 2010),

126 modulates eggshell microbiota (Bollinger et al. 2018; Cook et al. 2005a), may also have an 
127 antipredator function (Kreisinger \& Albrecht 2008; Morosinotto et al. 2013) and could play a role

128 in regulating hatching asynchrony (Magrath 1990). Whether partial incubation affects or

129 stabilises the egg content antimicrobial properties remains unknown. Furthermore, as an

130 increase in egg-white AMP concentration enhanced in vitro egg-white antimicrobial activity

131 against selected bacterial strains in our previous experimental study (Svobodová et al. 2019),

132 we hypothesise that different concentrations of egg-white AMPs will affect the probability and

133 intensity of bacterial trans-shell penetration in vivo. Finally, as egg-white lysozyme and avidin

134 have been shown to play a role in modulating hatching success, immune response and body

135 morphological traits of hatchlings in other precocial birds (Bonisoli-Alquati et al. 2010; Cucco et

136 al. 2007; Javưrková et al. 2015; Krkavcová et al. 2018), we predict that egg-white lysozyme and

137 avidin concentration will play a similar role in dictating mallard duckling morphological traits.

\section{Material \& Methods}

140 Ethical statement

141 All experiments and analyses were performed in accordance with relevant institutional

142 guidelines and regulations. The experiment was carried out under institutional permission No.

$14363479 / 2016-M Z E-17214$, issued by the Ministry of Agriculture on behalf of the Government of

144 the Czech Republic (see Supplementary Material - Experimental Permission).

146 Experimental procedures

147 Freshly laid mallard eggs were obtained $(n=160)$ from a commercial hatchery (Mokřiny Duck

148 Farm, Třeboň Fisheries Ltd, Czech Republic) in June 2010. To control for potential bias in the

149 variability of egg-white AMP concentration in experimental eggs due to female identity and egg

150 laying order (D'Alba et al. 2010; Valcu et al. 2019), the experimental eggs were collected

151 randomly at the same time over a single day, thereby ensuring that they came from a similar 
152 laying order sequence and from different females. Egg length and width were measured with 153 digital callipers (0.01 mm accuracy; Kinex, Prague, Czech Republic) in order to compute egg 154 volume (Rohwer 1988). Subsequently, each egg was cleaned with $70 \%$ ethanol to eliminate the 155 initial eggshell bacterial assemblage and then placed into sterile portable boxes.

156 Four randomly selected eggs were placed into each experimental nest $(N=40)$

157 distributed in typical mallard breeding habitat (Dívčice, Czech Republic, $49^{\circ} 6^{\prime} \mathrm{N}, 14^{\circ} 18^{\prime} \mathrm{E}$ ) and 158 exposed for nine days, corresponding to the mean mallard egg-laying period observed under 159 natural conditions (Krapu et al. 2004). The eggs in each experimental nest were sorted based 160 on a balanced $2 \times 2$ factorial design (see Supplementary Fig. S1), i.e. two eggs were covered 161 with a mixture of nest-lining feathers collected from active mallard nests (see details below), 162 while the other two eggs remained uncovered. Subsequently, two eggs (one covered and one 163 uncovered with nest-lining feathers) were incubated daily in an incubator (OvaEasy 190 Advance, Brinsea Products Inc., Titusville, FL, USA) for periods that mimicked the incubation pattern observed during the mallard pre-incubation period (see Loos \& Rohwer 2004, Javưrková et al. 2014; Supplementary Table S1). Experimentally incubated eggs were transferred from the experimental nests to the incubator and back each day in portable sterilised boxes. The experimentally incubated eggs were incubated for a total of 45 hours at $37.6{ }^{\circ} \mathrm{C}$, with a relative humidity of $60 \%$, over the nine days. The two remaining eggs from each experimental nest were not incubated, but were turned and handled daily to maintain a manipulation procedure identical to that of the eggs transferred for incubation. All experimental eggs were turned $180^{\circ}$ twice daily using rubber gloves to maintain optimal egg hatchability (Oliveira et al. 2020).

The nest-lining feathers used for egg covering were collected from several $(n=30)$,

174 randomly chosen, active mallard nests located within the Dívčice breeding habitat over May 175 2010. No more than $40-50 \%$ of nest-lining material was ever taken from the active mallard 176 nests to prevent nest desertion and reproductive failure of the breeding female. The nest-lining 
177 feathers were mixed before being used for the experimental treatment (i.e. covering of

178 experimental eggs by nest-lining feathers; see also Javůrková et al. 2014 for details).

179

180 Egg-white sampling and assessment of egg hatchability

181 Egg-white sampling procedures were identical to those described in detail in Javůrková et al.

182 (2014). In short, all experimental eggs were cleaned with $70 \%$ ethanol and the shell gently

183 perforated with a $22 \mathrm{G}(0.7 \times 40 \mathrm{~mm})$ sterile needle (Terumo®, Germany) at the blunt end.

184 Thereafter, $300 \mu \mathrm{L}$ of egg-white was removed with a $0.5-\mathrm{mL}$ sterile syringe (B Braun, Germany)

185 and placed in sterile cryotubes stored at $-20^{\circ} \mathrm{C}$ until egg-white AMP analysis. Needle

186 perforations in the eggshell were sealed using a gel-based adhesive (Loctite Super Attack,

187 Henkel, USA). Based on previous studies (Bonisoli-Alquati et al. 2007; Finkler et al. 1998), such

188 a procedure has no significant impact on egg hatchability.

189 The eggs were then placed back in an incubator with temperature at $37.6{ }^{\circ} \mathrm{C}$ and

190 relative humidity at $60 \%$, with relative humidity being increased to $80 \%$ during the egg-hatching

191 period in order to achieve optimal hatching conditions (Stubblefield \& Toll 1993). The weight ( \pm

$1920.1 \mathrm{~g})$ and tarsus length $( \pm 0.1 \mathrm{~mm})$ of each duckling was measured immediately after hatching

193 in order to obtain body mass condition indices (i.e. residual body mass and scaled body mass

194 index (BMI), see below for details).

195

196 Analysis of egg white AMP concentration

197 Concentration of egg-white lysozyme

198 Lysozyme concentration $(\mathrm{mg} / \mathrm{mL})$ was measured using the agar well-diffusion assay of

199 Osserman \& Lawlor (1966), which is described in detail in our previous studies (Javůrková et al.

200 2015; Svobodová et al. 2019). Briefly, 50mg of lyophilised Micrococcus lysodeikticus (Sigma-

201 Aldrich, ATTC 4698, M3770) was diluted in $10 \mathrm{~mL}$ of Britton-Robinson buffer (pH 7.0) prepared 
202 via adding $0.492 \mathrm{~g}$ boric acid, $0.782 \mathrm{~g} \mathrm{98 \%} \mathrm{phosphoric} \mathrm{acid,} 0.480 \mathrm{~g}$ acetic acid and $0.840 \mathrm{~g}$ $203 \mathrm{NaOH}$ into $305 \mathrm{ml}$ of distilled water. This suspension was added to a $60^{\circ} \mathrm{C}$ solution of $1 \%$ agar 204 (1 $\mathrm{g}$ of agar (Alchimica) re-suspended in $100 \mathrm{ml}$ of Britton-Robinson buffer) and poured into 205 Petri dishes and left for 30 min to solidify. Core borer was used to punch $3 \mathrm{~mm}$ diameter holes 206 into the agar. Then, homogenisation of each egg-white sample in a glass vial at $1800 \mathrm{rpm}$ for 15 207 min was conducted using an immersed cross spin magnetic stirrer bar $(12 \times 30 \mathrm{~mm})$ and a 208 magnetic stirrer (RH Digital, IKA, Oxford, UK). Subsequently, 10 $\mu \mathrm{L}$ of each egg-white sample 209 was transferred into the holes on the agar plates in duplicate. Standard solutions (10 $\mu \mathrm{L})$ of 210 lyophilised hen egg-white lysozyme (62971, Fluka) of known concentration $(20,15,7,4,2,0.5$ $211 \mathrm{mg} / \mathrm{mL}$ ) were also added to the punched holes in each agar plate. The plates were then 212 incubated for 24 hours at $21^{\circ} \mathrm{C}$ and $50-60 \%$ humidity. Diameters of clearance zones around the 213 holes were analysed from photographs using ImageJ. GraphPad Prism version 6.00 for 214 Windows (GraphPad Software, San Diego California USA) was used for interpolation of 215 lysozyme concentration $(\mathrm{mg} / \mathrm{mL})$ in each egg-white sample from a calibration curve.

216

217 Concentration of egg-white avidin

218 Avidin concentration $(\mu \mathrm{g} / \mathrm{mL})$ was based on a slightly modified version of the 96 -well plate 219 method of Gan \& Marquardt (1999) and Shawkey et al. (2008) for assessing the affinity of avidin 220 to biotin, which we used in our previous work (Krkavcová et al. 2018). Briefly, we diluted each 221 egg-white sample 10-fold in carbonate-bicarbonate buffer (Sigma-Aldrich C3041). Then, $100 \mu \mathrm{L}$ 222 of carbonate-bicarbonate buffer was added to each well (except the first, fifth and ninth well in 223 each row) along rows one to 11 of a Nunc MaxiSorp® flat-bottom 96-well plate (see also 224 Krkavcová et al. 2018). Then each 10-fold diluted egg-white sample was added in volume of $225100 \mu \mathrm{L}$ to empty wells 1,5 and 12 in each row making four serial dilutions for each of these 226 samples. Finally, $100 \mu \mathrm{L}$ of avidin standard solution (2.5-0.002 $\mu \mathrm{g} / \mathrm{mL}$; Sigma Aldrich; A9275)

227 diluted in carbonate-bicarbonate buffer was added to the wells in the bottom row. Accurate 
228 pipetting of undiluted and diluted egg-white samples was achieved using GENO-DNA S pipette 229 tips (CS960 9405120, Thermo Fisher Scientific) especially designed for viscous liquids. The 96230 well plate sealed with parafilm was then incubated at $4^{\circ} \mathrm{C}$ overnight. Then we applied same 231 procedures as was described in Krkavcová et al. (2018). Particularly, the content of the wells 232 was poured out and the plate rinsed three times by adding $200 \mu \mathrm{L}$ of $0.05 \%$ Tween washing 233 buffer (Tween 20/PBS) to each well and shaking for five minutes on an IKA KS 260 basic lab 234 shaker. Non-specific protein sites were blocked by adding $200 \mu \mathrm{L}$ of blocking buffer ( $1 \%$ solution 235 of bovine serum albumin (Sigma Aldrich) in PBS) to each well three times for $30 \mathrm{sec}$, after which $236100 \mu \mathrm{L}$ of a 1:4000 dilution of biotinylated biotin/HRP (Invitrogen, Thermo Fisher Scientific) in 237 Superblock buffer (0.05\% Tween 20/blocking buffer) was added to each well and incubated at 238 room temperature for 25 minutes. The wells were then washed five times with $200 \mu \mathrm{L}$ of 239 washing buffer, followed by $30 \mathrm{sec}$. shaking on the lab shaker. Then, $100 \mu \mathrm{L}$ of TMB Substrate 240 blocking buffer (Sigma Aldrich) was added to each well and the plate was incubated at room 241 temperature for $30 \mathrm{~min}$. Subsequent adding of $100 \mu \mathrm{L}$ of TMB Substrate Stop Reagent (Sigma 242 Aldrich) to each well and mixing it stopped reaction. Using a TECAN Infinite 8200 PRO UV/Vis

243 microplate reader (Tecan Group, Männedorf, Switzerland), we measured sample absorbance at $244450 \mathrm{~nm}$, with each sample analysed in duplicate. GraphPad Prism 5 Software was used for 245 interpolation of avidin concentrations (considering four egg-white serial dilutions) from a 246 standard curve for each plate (inter-assay and intra-assay coefficients of variability were $12.6 \%$ 247 and $3.2 \%$, respectively).

\section{Quantitative analysis of bacterial trans-shell penetration}

250 Quantitative measurement of bacterial trans-shell penetration (BTSP) was based on our 251 previously published method (Javůrková et al. 2014). In brief, bacterial genomic DNA was 252 extracted from egg-white samples using the EliGene MTB Isolation Kit (Elisabeth Pharmacon, 
253 Brno, Czech Republic). Microbial genomic DNA was then analysed for the incidence and 254 intensity of BTSP using RT-PCR based entirely on the targeting of 16S rRNA using an RT-PCR 255 LightCycler 480 system (Roche, Mannheim, Germany). The LightCycler 480 SYBR Green I 256 Master (Roche) and the universal Eubacteria primer set, including forward primer Uni331 (5'257 TCCTACGGGAGGCAGCAGT-3') and reverse primer Uni797 (5'-

258 GGACTACCAGGGTATCTAATCCTGTT-3'), were used for RT-PCR amplification (Horz et al. 259 2005). We used our previous approach for construction of calibration curves (Javưrková et al. 260 2014). Specifically, serial dilutions $\left(10^{1}\right.$ to $\left.10^{9}\right)$ of purified genomic Streptococcus bovis DNA 261 with a known number of bacterial cells were used. BTSP intensity was then expressed as 262 number of bacterial cells per $1 \mathrm{~mL}$ of egg-white. Relative incidence of BTSP (i.e. penetrated vs. 263 non-penetrated) was based on the successful amplification of diluted Streptococcus bovis DNA 264 which was a positive control for this assignment.

265

Amplification conditions protocol of Javůrková et al. (2014) was used for setting 266 amplification conditions. Specifically, the PCR reaction was performed in triplicate on a 267 LightCycler_ 480 Multiwell Plate 384 using a total volume of $10 \mu \mathrm{L}$, including $5 \mu \mathrm{L}$ of LightCycler 268 480 SYBR Green I Master, $3 \mu \mathrm{L}$ of PCR H2O (Top-Bio,Czech Republic), and $0.5 \mu \mathrm{L}$ of each 269 primer at concentrations of $5 \mu \mathrm{M}$ and $1 \mu \mathrm{L}$ of DNA template. Reaction conditions for DNA 270 amplification were following: one pre-amplification cycle at $95{ }^{\circ} \mathrm{C}$ for $10 \mathrm{~min}$ followed by 40 271 amplification cycles at $95^{\circ} \mathrm{C}$ for $10 \mathrm{~s}, 58{ }^{\circ} \mathrm{C}$ for $10 \mathrm{~s}$ and $72{ }^{\circ} \mathrm{C}$ for $30 \mathrm{~s}$ at a ramp rate of $4.8^{\circ} \mathrm{C} / \mathrm{s}$ 272 (Javưrková et al. 2014) Analysis of product melting was performed to determine specificity of 273 amplification. A melting curve was obtained by slow heating at $2.5^{\circ} \mathrm{C} / \mathrm{s}$ increments from $65^{\circ} \mathrm{C}$ to $27495^{\circ} \mathrm{C}$, with fluorescence collection at $0.5^{\circ} \mathrm{C}$ intervals (see also Javůrková et al. 2014). Efficiency 275 and slope values for particular RT-PCR runs $(n=3)$ were: 1.82 and 3.84; 2.14 and 3.03; and 1.94 276 and 3.71, respectively. 


\section{Statistics}

279 As AMP measurements were highly repeatable (interclass correlation coefficient $=0.861$ for

280 avidin and 0.953 for lysozyme), we used the average avidin and lysozyme concentration values

281 of each biological sample for all later analyses. Moreover, as concentrations of avidin and

282 lysozyme were not correlated (Spearman correlation, rho $=0.014, p=0.869$ ), we built separate

283 models for predicting concentrations of these two AMPs, or used both AMPs as separate model

284 predictors. Eggs were clustered into quadruplets during the experimental phase of our study,

285

which may have affected the probability of BTSP, as shown in our previous study (Javůrková et

286

al. 2014). To account for this source of data non-independence, quadruplet identities were

287

included as random intercepts into all models, unless otherwise stated.

288

Generalised Linear Mixed Models (GLMMs) with Gaussian distributed errors were used

289

to test whether egg volume was related to AMP concentration and whether AMP concentrations

290

were affected by partial incubation, clutch covering with nest-lining feathers or interactions

291

between these two variables. The effect of egg-white AMP concentration, along with effects of

292 the above-mentioned incubation treatments, on incidence of BTSP and hatching success were

analysed using logistic GLMMs (binomial error distribution, logit link). Next, using a subset of

eggs positive for BTSP (i.e. number of bacterial cells estimates per $1 \mathrm{ml}$ of albumen > 1) and

GLMMs with Gaussian error distribution, we assessed whether intensities of bacterial

penetration ( $\log ^{10}$ scaled) were predicted by concentrations of the two egg-white AMPs. Finally,

we assessed whether there was any association between AMP concentration and selected

hatchling morphological traits. As Peig \& Green (2009) showed that scaled BMI is a good

indicator of the relative size of energy reserves in a homogenous population, we used (i)

residual body mass adjusted for the effect of egg volume (i.e. residuals from a linear regression 
303 variables (Peig \& Green 2009), with AMP concentration, along with the effect of partial

304 incubation (known to affect hatchling morphological traits; see Javưrková et al. 2014), used as

305 predictors. AMP effect on phenotype traits was modelled using linear regression since mixed

306 models exhibited poor convergence on this data subset. Moreover, there were only two

307 quadruplets with more than a single egg successfully hatched, suggesting a negligible effect of

308 data non-independence on the outcomes of these analyses.

309 According to previous studies, there are significant temporal differences in AMP

310 concentrations. However, limited effort has been devoted to their causes. As data on avidin

311 concentrations exhibited skewed distribution, we used $\log ^{10}$ transformed values in all statistical

312 calculations. Models were fitted using the R package Ime4 (Bates et al. 2015) running in $R$

313 software (R-Core-Team 2020) and Rstudio version 1.1.453 (RStudio Team 2015). To select the

314 best minimal adequate model (MAM), i.e. the most parsimonious model with all effects

315 significant, backward elimination of non-significant terms in the GLMM was applied (Crawley

316 2007). During this process, non-significant interactions were eliminated as first followed by non-

317 significant main effects. Change in deviance between the model containing this term and the

318 reduced model assuming $\chi^{2}$ or $F$ distribution of difference in deviances was used for the

319 significance assignment of a particular explanatory variable Degrees of freedom were equal to

320 the difference in degrees of freedom between the models with and without the term in question

321 (Crawley 2007).

322

323 Results

324

325

Effect of partial incubation and clutch covering with nest-lining feathers on egg-white AMP 326 concentration 
327 There was no association between egg volume and lysozyme or avidin concentrations $(\Delta$ d.f. $=$ $3281, \chi^{2}=0.05, p=0.816$ and $\chi^{2}=0.33, p=0.566$, respectively; Table 1$)$. Lysozyme concentrations 329 was significantly higher in partially incubated eggs $\left(\Delta\right.$ d.f. $=1, \chi^{2}=25.72, p<0.001$; Table 1 , Fig.

330 1), while non-significant difference was observed for avidin ( $\Delta$ d.f. $=1, \chi^{2}=3.28, p=0.070$; Table

331 1, Fig. 1). Clutch covering, or the interaction between clutch covering and partial incubation, had 332 no effect on avidin and lysozyme concentration ( $p>0.300$ in all cases; Table 1$)$.

333

334 Effect of egg-white AMP concentration on BTSP

335 We detected BTSP in 91 of 160 experimental eggs (57\%), with a mean BTSP intensity of $3.4 \mathrm{x}$ $33610^{5}$ bacterial cells per $1 \mathrm{~mL}$ of egg white (range: $10^{2}-10^{4}$ bacterial cells per $1 \mathrm{~mL}$; see 337 Supplementary Fig. S2). Concentration of egg-white lysozyme and avidin had no effect on the 338 incidence of BTSP $\left(\Delta\right.$ d.f. $=1, \chi^{2}=0.05, p=0.82$ and $\Delta$ d.f. $=1, \chi^{2}=0.01, p=0.999$, respectively; 339 Table 2), and incidence of BTSP was unaffected by the interaction between AMP concentration 340 and experimental treatment ( $p>0.2$ in all cases; Table 2). There was also no correlation between 341 intensity of BTSP and egg-white lysozyme $\left(\Delta\right.$ d.f. $=1, \chi^{2}=0.42, p=0.517 ;$ Table 2$)$ or avidin $(\Delta$ 342 d.f. $=1, \chi^{2}=2.64, p=0.104 ;$ Table 2 ) concentrations in a subset of penetrated eggs.

\section{Effect of egg-white AMP concentration on hatching success}

345 In the present study, we found that higher hatching success of partially incubated eggs was 346 unaffected by egg volume (GLMM with binary response: $\Delta$ d.f. $=1, x^{2}=0.056, p=0.813$ ), or egg347 white lysozyme and avidin concentrations $\left(\Delta\right.$ d.f. $=1, \chi^{2}=1.26, p=0.262$ and $\Delta$ d.f. $=1, \chi^{2}=1.58$, $348 p=0.209$, respectively; Table 3) Similarly, we found no support for any interaction between both 349 AMP concentrations and experimental treatments on hatching success $(p>0.1$ in all cases, Table $3503)$. 
352 Effect of egg-white AMP concentration on hatchling phenotype

353 Partially incubated eggs produced hatchlings with significantly reduced residual body mass and 354 scaled BMI $\left(F_{(1,25)}=23.98, p<0.001\right.$ and $F_{(1,24)}=10.97, p=0.002$, respectively; Table 4). When 355 accounting for this source of variation, we observed no effect of AMP concentration on residual 356 body mass $\left(F_{(1,24)}=0.02, p=0.903\right.$ for lysozyme and $F_{(1,24)}=0.01, p=0.935$ for avidin; Table 4).

357 At the same time, avidin failed to predict variation in scaled $B M I\left(F_{(1,23)}=0.14, p=0.711\right.$; Table 358 4); however, scaled BMI was significantly reduced in hatchlings originated from eggs with higher 359 concentrations of egg white lysozyme $\left(F_{(1,24)}=7.23, p=0.013\right)$ after statistical control for the variation induced by partial incubation (Table 4, Fig. 2).

\section{Discussion}

363 In the present study, partial incubation of mallard eggs caused alterations in the concentration of 364 egg-white AMPs, with lysozyme showing a significantly higher concentration in partially incubated eggs. This concurs with a recent study that compared the proteomic profile of fertile chicken eggs during the first 12 days of incubation, demonstrating a substantially higher egg-white lysozyme content in fertilised eggs at day 12 compared with non-incubated eggs at day 0 (Zhu et al. 2019). Similarly, Guyot et al. (2016b) observed a gradual increase in egg-white protein concentration from day 0 to 12 of incubation in fertilised chicken eggs. It is important to note here that additional egg-white protein synthesis is impossible after oviposition; hence, the observed higher egg-white protein concentration in partially incubated eggs is most probably the result of a substantial loss

372 of water from the egg white during partial incubation due to embryo growth, the synthesis of 373 embryonic membranes and extraembryonic fluids, and evaporation (Guyot et al. 2016b; Romanoff 374 and Romanoff 1933). In our previous experimental study, however, partial incubation had a non375 significant effect on egg-white lysozyme concentrations in quail (Coturnix japonica) and pigeon 
376 (Columba livia domestica) eggs (Svobodová et al. 2019), while other studies have documented 377 either a slight decrease in egg-white lysozyme in chicken eggs during the early phase of full 378 incubation (Fang et al. 2012a; Fang et al. 2012b), or a decrease in egg-white lysozyme 379 concentration in precocial chicken eggs (Cunningham 1974) and altricial red-capped lark eggs 380 (Grizard et al. 2015) following full incubation. Clearly, there is inconsistency as regards 381 temperature-induced changes in egg-white AMPs under different incubation modes. While this 382 might suggest that different embryonic developmental stages are playing a role (see Guyot et al. 383 2016b), other studies have suggested that egg-white lysozyme decreases due to protein 384 aggregation (Liu et al. 2015; Qiu et al. 2012), lysozyme binding to other proteins (Kato et al. 1975) 385 or lysozyme degradation soon after incubation (Fang et al. 2012a). Recent works, however, have 386 suggested that thermal aggregation of proteins, and the resulting changes in protein abundance, 387 are highly dependent on the content of particular amino acids, such as arginine, lysine or aspartic 388 acid, which act as protein stabilisers and/or destabilisers (Anumalla \& Prabhu 2019; Hong et al. 389 2017). Further, temperature-induced levels of protein aggregation have been shown to be linked with the concentration of other heat-sensitive egg-white proteins, such as ovotransferrin (Iwashita et al. 2019). As proteomic and amino acid profiles vary considerably between species (Shawkey et al. 2008; Sun et al. 2017), it is highly likely that, in addition to changes attributable to water loss 393 (Guyot et al. 2016b; Romanoff and Romanoff 1933), observed differences in egg-white lysozyme 394 concentration could be the result of differing ratios and concentrations of aggregation-preventing arginine and/or ovotransferrin in the mallard eggs used in our study. Unfortunately, we were unable to test for such associations in this study as the results for replicate measurements of eggwhite ovotransferrin concentration were highly variable. While further experimental testing is needed to prove the relationship with aggregation-preventing egg-white substances, we suggest that the potential for such effects should be considered during future research focused on the 400 thermal properties of egg-white. 

403 the incidence or intensity of BTSP. This was still true following the significantly higher 404 concentration of egg-white lysozyme in partially incubated eggs. This finding is supported by a 405 recent experimental study of Baron et al. (2020) testing the effect of egg-white proteins (egg-white 406 fraction $>10 \mathrm{kDa}$ ) on egg-white anti-Salmonella activity, demonstrating that presence of egg-white 407 proteins played a minor role in the bactericidal activity of egg white at $45^{\circ} \mathrm{C}$, suggesting that egg408 white low-mass components $(<10 \mathrm{kDa})$ have a greater impact on temperature-induced 409 bactericidal activity of chicken egg white at $45^{\circ} \mathrm{C}$. On the contrary, in our previous experimental 410 study, egg whites enriched in ovo with hen egg-white lysozyme significantly increased their in 411 vitro antimicrobial action against indicator strains (Svobodová et al. 2019). To date, however, 412 there have been no studies evaluating the in vivo antimicrobial potential of naturally varying eggwhite AMPs or associated trans-shell microbial penetrations. In our previous study, we also noted selective in vitro antimicrobial activity in egg whites from precocial eggs treated with partial incubation, with enhanced proliferation of a beneficial probiotic bacterial strain (Svobodová et al. 2019). Similarly, incubation was shown to shift eggshell microbiota diversity from initially diverse communities that included opportunistic pathogens toward less diverse communities with less harmful, or even beneficial, microorganisms dominating (Grizard et al. 2014; Lee et al. 2014). It would appear, therefore, that partial incubation as a mechanism acts outside the egg to modulate eggshell microbial communities toward harmless or beneficial microorganisms, and inside the

421 egg to maintain beneficial bacterial invaders. Moreover, the protective roles of incubation and 422 egg-white AMPs against pathogenic microorganisms appears to be most effective during the early 423 phase of embryonic development, while developing extra-embryonic structures appear to play a 424 greater protective role later in the incubation process (Guyot et al. 2016b; Hincke et al. 2019). 425 Clearly, therefore, the role of egg-white AMPs in modulating microbial trans-shell invaders during 
426 different incubation phases is complex, and more in vivo studies will be needed to fully understand 427 the mechanisms behind this complexity.

428 Previous studies have found that egg-white lysozyme has a beneficial maternal effect 429 when deposited into the eggs by the female of precocial (Bonisoli-Alquati et al. 2010; Cucco et al. 430 2007, Kozuszek et al. 2009) and altricial birds (Boonyarittichaikij et al. 2018), resulting in a higher 431 egg hatching rate (Cucco et al. 2007) or improved hatchability and immunocompetence of 432 nestlings (Saino et al. 2002). However, our results indicate that higher egg-white lysozyme levels 433 may also had a negative impact on hatchling body condition (expressed as scaled BMI). This is 434 in accordance with our previous study, where an experimental increase in egg-white lysozyme in 435 precocial quail eggs resulted in a reduced tarsus length in hatchlings (Javůrková et al. 2015). 436 While the mechanism of action is not yet clear, lysozyme is known to play a growth-regulating 437 role in the development of embryonic cartilage and skeletal structures (Kuettner et al. 1970), 438 including inhibition of mouse bone collagenase activity, which could significantly affect development of particular skeletal elements (Sakamoto et al. 1974).

440 In this study, egg-white avidin concentration appeared to have no impact on mallard 441 hatchling phenotype. While we previously documented egg-white avidin as altering chick 442 phenotype in quail (Krkavcová et al. 2018), the growth-inhibition effect in this case was strongly 443 dependent on egg weight, since only those chicks originating from lighter eggs enriched with 444 avidin in ovo had a reduced tarsus length. It follows, therefore, that while egg-white AMPs may 445 fulfil a protective antimicrobial role for the embryo during the early phases of embryo development, 446 increases in their concentration may significantly compromise embryo growth and negatively 447 affect hatchling morphological traits and condition in precocial birds.

448 As in the case of partial incubation, we failed to find any effect of clutch covering with nest449 lining feathers on egg-white AMPs or incidence and intensity of bacterial trans-shell penetration. 450 Though clutch covering has been shown to insulate eggs against ambient temperatures (Pinowski 451 et al. 2006; Prokop \& Trnka 2011), it would appear that its main purpose is to maintain eggs at 
452 optimal temperatures around physiological zero, thereby sustaining egg viability and improving 453 hatchability and hatchling growth performance (Dawson et al. 2011; Peralta-Sanchez et al. 2011; 454 Stephenson et al. 2009), rather than to alter temperatures to levels that lead to changes in the 455 egg-white AMP profile. Just two studies have shown that nest material and nest-lining feathers 456 have a strong antimicrobial effect, both indicating an ability to shift eggshell microbiota in hoopoe 457 (Upupa epops) (Ruiz-Castellano et al. 2019; Ruiz-Castellano et al. 2016). As evidence for the 458 antimicrobial action of nest-lining feathers is lacking in other bird species, and we observed no 459 effect of alteration of egg-white AMPs on bacterial trans-shell penetration, it is highly likely that 460 nest-lining feathers in our study species may only have an antimicrobial effect on the eggshell 461 itself, without affecting the antimicrobial potential of egg-white; alternatively, its primary function 462 may be clutch insulation and/or protection against visually-oriented predators (Kreisinger \& 463 Albrecht 2008).

464

\section{Conclusions}

466 We were able to show that partial incubation, a behavioural mechanism having a range of 467 functions, from antipredator nest protection to maintaining egg viability, also has the ability to 468 alter concentrations of particular egg-white AMPs during the pre-incubation phase. Furthermore, 469 while concentrations of particular egg-white AMPs were not associated with reduced intensity 470 and incidence of bacterial trans-shell penetration in eggs of a precocial bird in vivo, increased 471 concentration of egg-white lysozyme may play a growth-modulating role during embryogenesis, 472 at least in our precocial model species. While the growth-modulating role of particular egg-white 473 AMPs during the various developmental stages of avian embryos requires further testing, our 474 results are some of the first to point out these potential relationships.

475

\section{Acknowledgements}


477 We thank Eva Krkavcová for her help in the laboratory and for the AMP concentrations analysis,

478 and Kevin Roche for professional English proofreading.

479

480

\section{References}

481

482

483

484

485

486

487

488

489

490

491

492

493

494

495

496

497

498

499

500

501

502

503

504

505

506

507

508

509

510

511

512

513

514

515

516

517

518

519

520

521

522
Anumalla B, and Prabhu NP. 2019. Counteracting Effect of Charged Amino Acids Against the Destabilization of Proteins by Arginine. Applied Biochemistry and Biotechnology 189:541-

555. 10.1007/s12010-019-03026-w

Bain MM, McDade K, Burchmore R, Law A, Wilson PW, Schmutz M, Preisinger R, and Dunn IC. 2013. Enhancing the egg's natural defence against bacterial penetration by increasing cuticle deposition. Animal Genetics 44:661-668. 10.1111/age.12071

Baron F , Cochet MF, Alabdeh M, Guerin-Dubiard C, Gautier M, Nau F, Andrews SC, Bonnassie S, and Jan S. 2020. Egg-White Proteins Have a Minor Impact on the Bactericidal Action of Egg White Toward Salmonella Enteritidis at 45 degrees C. Frontiers in Microbiology 11: 584986.10.3389/fmicb.2020.584986

Baron F, and Jan S. 2011. Egg and egg product microbiology. In: Nys Y, Bain M, and Immerseel FV, eds. Improving the Safety and Quality of Eggs and Egg Products. Cambridge, UK: Woodhead Publishing Ltd, 330-350.

Bates D, Machler M, Bolker BM, and Walker SC. 2015. Fitting Linear Mixed-Effects Models Using Ime4. Journal of Statistical Software 67:1-48.

Board RG, and Fuller R. 1974. Nonspecific antimicrobial defences of avian egg, embryo and neonate. Biological Reviews of the Cambridge Philosophical Society 49:15-\&. 10.1111/j.1469-185X.1974.tb01297.x

Bollinger PB, Bollinger EK, Daniel SL, Gonser RA, and Tuttle EM. 2018. Partial incubation during egg laying reduces eggshell microbial loads in a temperate-breeding passerine. Journal of Avian Biology 49. 10.1111/jav.01560

Boonyarittichaikij R, Verbrugghe E, Dekeukeleire D, Strubbe D, Van Praet S, De Beelde R, Rouffaer L, Pasmans F, Bonte D, Verheyen K, Lens L, and Marte A. 2018. Mitigating the impact of microbial pressure on great (Parus major) and blue (Cyanistes caeruleus) tit hatching success through maternal immune investment. PLOS ONE 13:10. 10.1371/journal.pone.0204022

Bonisoli-Alquati A, Rubolini D, Romano M, Boncoraglio G, Fasola M, and Saino N. 2007. Effects of egg albumen removal on yellow-legged gull chick phenotype. Functional Ecology 21:310-316. 10.1111/j.1365-2435.2006.01226.x

Bonisoli-Alquati A, Rubolini D, Romano M, Cucco M, Fasola M, Caprioli M, and Saino N. 2010. Egg antimicrobials, embryo sex and chick phenotype in the yellow-legged gull. Behavioral Ecology and Sociobiology 64:845-855. 10.1007/s00265-010-0901-8

Calatayud M, Koren O, and Collado MC. 2019. Maternal Microbiome and Metabolic Health Program Microbiome Development and Health of the Offspring. Trends in Endocrinology and Metabolism 30:735-744. 10.1016/j.tem.2019.07.021

Campos-Cerda F, and Bohannon BJM. 2020. The Nidobiome: A Framework for Understanding Microbiome Assembly in Neonates. Trends in Ecology \& Evolution 35:573-582. 10.1016/j.tree.2020.03.007

Chen CY, Chen CK, Chen YY, Fang A, Shaw GTW, Hung CM, and Wang D. 2020. Maternal gut microbes shape the early-life assembly of gut microbiota in passerine chicks via nests. Microbiome 8. 10.1186/s40168-020-00896-9

Peer) reviewing PDF | (2021:05:60948:2:1:NEW 2 Sep 2021) 
523

524

525

526

527

528

529

530

531

532

533

534

535

536

537

538

539

540

541

542

543

544

545

546

547

548

549

550

551

552

553

554

555

556

557

558

559

560

561

562

563

564

565

566

567

568

569

570

571

572

573
Cook MI, Beissinger SR, Toranzos GA, and Arendt WJ. 2005a. Incubation reduces microbial growth on eggshells and the opportunity for trans-shell infection. Ecology Letters 8:532537. 10.1111/j.1461-0248.2005.00748.x

Cook MI, Beissinger SR, Toranzos GA, Rodriguez RA, and Arendt WJ. 2003. Trans-shell infection by pathogenic micro-organisms reduces the shelf life of non-incubated bird's eggs: a constraint on the onset of incubation? Proceedings of the Royal Society BBiological Sciences 270:2233-2240. 10.1098/rspb.2003.2508

Cook MI, Beissinger SR, Toranzos GA, Rodriguez RA, and Arendt WJ. 2005b. Microbial infection affects egg viability and incubation behavior in a tropical passerine. Behavioral Ecology 16:30-36. 10.1093/beheco/arh131

Crawley MJ. 2007. The R Book: John Wiley \& Sons, Ltd.

Cucco M, Guasco B, Malacarne G, and Ottonelli R. 2007. Effects of $\beta$-carotene on adult immune condition and antibacterial activity in the eggs of the Grey Partridge, Perdix perdix. Comparative Biochemistry and Physiology Part A: Molecular \& Integrative Physiology 147:1038-1046.

Cunningham FE. 1974. Changes in egg-white during incubation of fertile egg. Poultry Science 53:1561-1565. 10.3382/ps.0531561

D'Alba L, Jones DN, Badawy HT, Eliason CM, and Shawkey MD. 2014. Antimicrobial properties of a nanostructured eggshell from a compost-nesting bird. Journal of Experimental Biology 217:1116-1121. 10.1242/jeb.098343D'Alba L, Oborn A, and Shawkey MD. 2010. Experimental evidence that keeping eggs dry is a mechanism for the antimicrobial effects of avian incubation. Naturwissenschaften 97:1089-1095. 10.1007/s00114-010$0735-2$

D'Alba L, Shawkey MD, Korsten P, Vedder O, Kingma SA, Komdeur J, and Beissingger SR. 2010. Differential deposition of antimicrobial proteins in blue tit (Cyanistes caeruleus) clutches by laying order and male attractiveness. Behavioral Ecology and Sociobiol 64:1037-1045. 10.1007/s00265-010-0919-y

D'Alba L, Torres R, Waterhouse GIN, Eliason C, Hauber ME, and Shawkey MD. 2017. What Does the Eggshell Cuticle Do? A Functional Comparison of Avian Eggshell Cuticles. Physiological and Biochemical Zoology 90:588-599. 10.1086/693434

Dawson RD, O'Brien EL, and Mlynowski TJ. 2011. The price of insulation: costs and benefits of feather delivery to nests for male tree swallows Tachycineta bicolor. Journal of Avian Biology 42:93-102. 10.1111/j.1600-048X.2010.05208.x

Diaz-Lora S, Martin-Vivaldi M, Juarez Garcia-Pelayo N, Azcarate Garcia M, Rodriguez-Ruano SM, Martinez-Bueno M, and Jose Soler J. 2019. Experimental old nest material predicts hoopoe Upupa epops eggshell and uropygial gland microbiota. Journal of Avian Biology 50. 10.1111/jav.02083

Fang J, Ma MH, Jin YG, Qiu N, Huang Q, Sun SG, Geng F, and Guo L. 2012a. Liquefaction of albumen during the early incubational stages of the avian embryo and its impact on the antimicrobial activity of albumen. Journal of Food Agriculture \& Environment 10:423-427.

Fang J, Ma MH, Jin YG, Qiu N, Ren GD, Huang X, and Wang C. 2012b. Changes in the antimicrobial potential of egg albumen during the early stages of incubation and its impact on the growth and virulence response of Salmonella Enteritidis. Italian Journal of Animal Science 11. 10.4081/ijas.2012.e17

Finkler MS, Van Orman JB, and Sotherland PR. 1998. Experimental manipulation of egg quality in chickens: influence of albumen and yolk on the size and body composition of nearterm embryos in a precocial bird. Journal of Comparative Physiology B-Biochemical Systemic and Environmental Physiology 168:17-24. 10.1007/s003600050116

Gan ZB, and Marquardt RR. 1999. Colorimetric competitive inhibition method for the quantitation of avidin, streptavidin and biotin. Journal of Biochemical and Biophysical Methods 39:1-6. 10.1016/s0165-022x(98)00051-7 
574

575

576

577

578

579

580

581

582

583

584

585

586

587

588

589

590

591

592

593

594

595

596

597

598

599

600

601

602

603

604

605

606

607

608

609

610

611

612

613

614

615

616

617

618

619

620

621

622

623
Gautron J, Rehault-Godbert S, Pascal G, Nys Y, and Hincke MT. 2011. Ovocalyxin-36 and other LBP/BPI/PLUNC-like proteins as molecular actors of the mechanisms of the avian egg natural defences. Biochemical Society Transactions 39:971-976. 10.1042/bst0390971

Grellet-Tinner G, Lindsay S, and Thompson MB. 2017. The biomechanical, chemical and physiological adaptations of the eggs of two Australian megapodes to their nesting strategies and their implications for extinct titanosaur dinosaurs. Journal of Microscopy 267:237-249. 10.1111/jmi.12572

Grizard S, Dini-Andreote F, Tieleman BI, and Salles JF. 2014. Dynamics of bacterial and fungal communities associated with eggshells during incubation. Ecology and Evolution 4:11401157. 10.1002/ece3.1011

Grizard S, Versteegh MA, Ndithia HK, Salles JF, and Tieleman BI. 2015. Shifts in Bacterial Communities of Eggshells and Antimicrobial Activities in Eggs during Incubation in a Ground-Nesting Passerine. Plos One 10. 10.1371/journal.pone.0121716

Guyot N, Labas V, Harichaux G, Chesse M, Poirier JC, Nys Y, and Rehault-Godbert S. 2016a. Proteomic analysis of egg white heparin-binding proteins: towards the identification of natural antibacterial molecules. Scientific Reports 6. 10.1038/srep27974

Guyot N, Rehault-Godbert S, Slugocki C, Harichaux G, Labas V, Helloin E, and Nys Y. 2016b. Characterization of egg white antibacterial properties during the first half of incubation: $A$ comparative study between embryonated and unfertilized eggs. Poultry Science 95:2956-2970. 10.3382/ps/pew271

Hincke MT, Da Silva M, Guyot N, Gautron J, McKee MD, Guabiraba-Brito R, and RehaultGodbert S. 2019. Dynamics of Structural Barriers and Innate Immune Components during Incubation of the Avian Egg: Critical Interplay between Autonomous Embryonic Development and Maternal Anticipation. Journal of Innate Immunity 11:111-124. $10.1159 / 000493719$

Hong TH, Iwashita K, Handa A, and Shiraki K. 2017. Arginine prevents thermal aggregation of hen egg white proteins. Food Research International 97:272-279. 10.1016/j.foodres.2017.04.013

Horz HP, Vianna ME, Gomes B, and Conrads G. 2005. Evaluation of universal probes and primer sets for assessing total bacterial load in clinical samples: General implications and practical use in endodontic antimicrobial therapy. Journal of Clinical Microbiology 43:5332-5337. 10.1128/jcm.43.10.5332-5337.2005

Ibrahim HR. 2019. Innate Antimicrobial Proteins and Peptides of Avian Egg. Eggs as Functional Foods and Nutraceuticals for Human Health 14:211-222.

Ibrahim HR, Matsuzaki T, and Aoki T. 2001. Genetic evidence that antibacterial activity of lysozyme is independent of its catalytic function. Febs Letters 506:27-32. 10.1016/s0014-5793(01)02872-1

Ishikawa S, Suzuki K, Fukuda E, Arihara K, Yamamoto Y, Mukai T, and Itoh M. 2010. Photodynamic antimicrobial activity of avian eggshell pigments. Febs Letters 584:770774. 10.1016/j.febslet.2009.12.041

Iwashita K, Handa A, and Shiraki K. 2019. Co-aggregation of ovotransferrin and lysozyme. Food Hydrocolloids 89:416-424. 10.1016/j.foodhyd.2018.11.022

Javůrková V, Albrecht T, Mrazek J, and Kreisinger J. 2014. Effect of intermittent incubation and clutch covering on the probability of bacterial trans-shell infection. Ibis 156:374-386. 10.1111/ibi.12126

Javưrková V, Krkavcova E, Kreisinger J, HyrsI P, and Hyankova L. 2015. Effects of experimentally increased in ovo lysozyme on egg hatchability, chicks complement activity, and phenotype in a precocial bird. Journal of Experimental Zoology Part aEcological Genetics and Physiology 323:497-505. 10.1002/jez.1935

Peer] reviewing PDF | (2021:05:60948:2:1:NEW 2 Sep 2021) 
624

625

626

627

628

629

630

631

632

633

634

635

636

637

638

639

640

641

642

643

644

645

646

647

648

649

650

651

652

653

654

655

656

657

658

659

660

661

662

663

664

665

666

667

668

669

670

671

672

Kato A, Imoto T, and Yagishita K. 1975. Binding groups in ovomucin-lysozyme interaction. Agricultural and Biological Chemistry 39:541-544. 10.1080/00021369.1975.10861614

Kozuszek R , Kontecka H , Nowaczewski S , Leśnierowski G, Kijowski J and Rosiński A. 2009. Quality of pheasant (Phasianus colchicus L.) eggs with different shell colour. Archiv fur Geflugelkunde 73:201-207.

Krapu GL, Reynolds RE, Sargeant GA, and Renner RW. 2004. Patterns of variation in clutch sizes in a guild of temperate-nesting dabbling ducks. Auk 121:695-706. 10.1642/00048038(2004)121[0695:povics]2.0.co;2

Kreisinger J, and Albrecht T. 2008. Nest protection in mallards Anas platyrhynchos: untangling the role of crypsis and parental behaviour. Functional Ecology 22:872-879. 10.1111/j.1365-2435.2008.01445.x

Krkavcova E, Kreisinger J, Hyankova L, Hyrsl P, and Javůrková V. 2018. The hidden function of egg white antimicrobials: egg weight-dependent effects of avidin on avian embryo survival and hatchling phenotype. Biology Open 7:9. 10.1242/bio.031518

Kuettner KE, Soble LW, Ray RD, Croxen RL, Passovoy M, and Eisenstein R. 1970. Lysozyme in epiphyseal cartilage .2. Effect of egg white lysozyme on mouse embryonic femurs in organ cultures. Journal of Cell Biology 44:329-+. 10.1083/jcb.44.2.329

Lee SI, Lee H, Jablonski PG, Choe JC, and Husby M. 2017. Microbial abundance on the eggs of a passerine bird and related fitness consequences between urban and rural habitats. Plos One 12:17. 10.1371/journal.pone.0185411

Lee WY, Kim M, Jablonski PG, Choe JC, and Lee SI. 2014. Effect of Incubation on Bacterial Communities of Eggshells in a Temperate Bird, the Eurasian Magpie (Pica pica). Plos One 9:11. 10.1371/journal.pone.0103959

Liu YJ, Qiu N, and Ma MH. 2015. Comparative proteomic analysis of egg white proteins during the rapid embryonic growth period by combinatorial peptide ligand libraries. Poultry Science 94:2495-2505. 10.3382/ps/pev176

Loos ER, and Rohwer FC. 2004. Laying-stage nest attendance and onset of incubation in prairie nesting ducks. Auk 121:587-599. 10.1642/00048038(2004)121[0587:Inaaoo]2.0.co;2

Magrath RD. 1990. Hatching asynchrony in altricial birds. Biological Reviews 65:587-622.

Mann K, and Mann M. 2011. In-depth analysis of the chicken egg white proteome using an LTQ Orbitrap Velos. Proteome Science 9:6. 10.1186/1477-5956-9-7

Martin-Vivaldi M, Soler JJ, Peralta-Sanchez JM, Arco L, Martin-Platero AM, Martinez-Bueno M, Ruiz-Rodriguez M, and Valdivia E. 2014. Special structures of hoopoe eggshells enhance the adhesion of symbiont-carrying uropygial secretion that increase hatching success. Journal of Animal Ecology 83:1289-1301. 10.1111/1365-2656.12243

Martinez-Garcia A, Martin-Vivaldi M, Rodriguez-Ruano SM, Peralta-Sanchez JM, Valdivia E, and Soler JJ. 2016. Nest Bacterial Environment Affects Microbiome of Hoopoe Eggshells, but Not That of the Uropygial Secretion. Plos One 11:15. 10.1371/journal.pone.0158158

Morosinotto C, Thomson RL, and Korpimaki E. 2013. Plasticity in incubation behaviour under experimentally prolonged vulnerability to nest predation. Behaviour 150:1767-1786. 10.1163/1568539x-00003119

Oliveira GD, dos Santos VM, Rodrigues JC, and Nascimento ST. 2020. Effects of different egg turning frequencies on incubation efficiency parameters. Poultry Science 99:4417-4420. 10.1016/j.psj.2020.05.045

Osorio JS. 2020. Gut health, stress, and immunity in neonatal dairy calves: the host side of host-pathogen interactions. Journal of Animal Science and Biotechnology 11. 10.1186/s40104-020-00509-3 
673

674

675

676

677

678

679

680

681

682

683

684

685

686

687

688

689

690

691

692

693

694

695

696

697

698

699

700

701

702

703

704

705

706

707

708

709

710

711

712

713

714

715

716

717

718

719

720

721

722

723
Osserman EF, and Lawlor DP. 1966. Serum and urinary lysozyme (muramidase) in monocytic and monomyelocytic leukemia. Journal of Experimental Medicine 124:921-52. 10.1084/jem.124.5.921

Peig J, and Green AJ. 2009. New perspectives for estimating body condition from mass/length data: the scaled mass index as an alternative method. Oikos 118:1883-1891. 10.1111/j.1600-0706.2009.17643.x

Peralta-Sanchez J, Martin-Platero AM, Wegener-Parfrey L, Martinez-Bueno M, RodriguezRuano S, Navas-Molina JA, Vazquez-Baeza Y, Martin-Galvez D, Martin-Vivaldi M, Ibanez-Alamo JD, Knight R, and Soler JJ. 2018. Bacterial density rather than diversity correlates with hatching success across different avian species. Fems Microbiology Ecology 94. 10.1093/femsec/fiy022

Peralta-Sanchez JM, Moller AP, and Soler JJ. 2011. Colour composition of nest lining feathers affects hatching success of barn swallows, Hirundo rustica (Passeriformes: Hirundinidae). Biological Journal of the Linnean Society 102:67-74. 10.1111/j.10958312.2010.01557.x

Pierce EC, Morin M, Little JC, Liu RB, Tannous J, Keller NP, Pogliano K, Wolfe BE, Sanchez LM, and Dutton RJ. 2021. Bacterial-fungal interactions revealed by genome-wide analysis of bacterial mutant fitness. Nature Microbiology 6:87-102. 10.1038/s41564-02000800-z

Pinowski J, Haman A, Jerzak L, Pinowska B, Barkowska M, Grodzki A, and Haman K. 2006. The thermal properties of some nests of the Eurasian Tree Sparrow Passer montanus. Journal of Thermal Biology 31:573-581. 10.1016/j.jtherbio.2006.05.007

Prokop P, and Trnka A. 2011. Why do grebes cover their nests? Laboratory and field tests of two alternative hypotheses. Journal of Ethology 29:17-22. 10.1007/s10164-010-0214-4

Qiu N, Ma MH, Cai ZX, Jin YG, Huang X, Huang Q, and Sun SG. 2012. Proteomic analysis of egg white proteins during the early phase of embryonic development. Journal of Proteomics 75:1895-1905. 10.1016/j.jprot.2011.12.037

R-Core-Team. R: A language and environment for statistical computing, http://www.R-proje ct.org/ (2020).

RStudio Team. RStudio: Integrated Development for R. RStudio, Inc., Boston, MA URL http://www.rstudio.com/ (2015).

Rohwer FC. 1988. Inter- and intraspecific relationships between egg size and clutch size in waterfowl. Auk 105:161-176.

Romanoff AL, and Romanoff AJ. 1933. Gross assimilation of yolk and albumen in the development of the egg of gallus domesticus. Anatomical Record 55:271-278. 10.1002/ar.1090550306

Ruiz-Castellano C, Ruiz-Rodriguez M, Tomas G, and Jose Soler J. 2019. Antimicrobial activity of nest-lining feathers is enhanced by breeding activity in avian nests. Fems Microbiology Ecology 95. 10.1093/femsec/fiz052

Ruiz-Castellano C, Tomas G, Ruiz-Rodriguez M, Martin-Galvez D, and Soler JJ. 2016. Nest Material Shapes Eggs Bacterial Environment. Plos One 11:21. 10.1371/journal.pone.0148894

Ruiz-De-Castaneda R, Vela Al, Gonzalez-Braojos S, Briones V, and Moreno J. 2011. Drying eggs to inhibit bacteria: Incubation during laying in a cavity nesting passerine. Behavioural Processes 88:142-148. 10.1016/j.beproc.2011.08.012

Ruiz-de-Castaneda R, Vela Al, Lobato E, Briones V, and Moreno J. 2012. Early onset of incubation and eggshell bacterial loads in a temperate-zone cavity-nesting passerinE. Condor 114:203-211. 10.1525/cond.2011.100230

Saino N, Dall'ara P, Martinelli R, and Moller AP. 2002. Early maternal effects and antibacterial immune factors in the eggs, nestlings and adults of the barn swallow. Journal of Evolutionary Biology 15: 735-743. 10.1046/j.1420-9101.2002.00448.x 
724

725

726

727

728

729

730

731

732

733

734

735

736

737

738

739

740

741

742

743

744

745

746

747

748

749

750

751

752

753

754

755

756

757

758

759

760

761

762

763

764

765

766

767

768

769

770

771

772

773

774

Saino N, Martinelli R, Biard C, Gil D, Spottiswoode CN, Rubolini D, Surai PF, and Moller, AP. 2007. Maternal immune factors and the evolution of secondary sexual characters. Behavioral Ecology 18: 513-520. 10.1093/beheco/arm004

Sakamoto S, Sakamoto M, Goldhaber P, and Glimcher MJ. 1974. Inhibition of mouse bone collagenase by lysozyme. Calcified Tissue Research 14:291-299. 10.1007/bf02060303

Shawkey MD, Kosciuch KL, Liu M, Rohwer FC, Loos ER, Wang JM, and Beissinger SR. 2008. Do birds differentially distribute antimicrobial proteins within clutches of eggs? Behavioral Ecology 19:920-927. 10.1093/beheco/arn019

Stephenson S, Hannon S, and Proctor H. 2009. The function of feathers in tree swallow nests: insulation or ectoparasite barrier? Condor 111:479-487. 10.1525/cond.2009.090074

Stubblefield WA, and Toll PA. 1993. Effects of incubation-temperature and warm-water misting on hatching success in artificially incubated mallard duck eggs. Environmental Toxicology and Chemistry 12:695-700. 10.1002/etc.5620120411

Sun CJ, Liu JN, Li WB, Xu GY, and Yang N. 2017. Divergent Proteome Patterns of Egg Albumen from Domestic Chicken, Duck, Goose, Turkey, Quail and Pigeon. Proteomics 17:12. 10.1002/pmic.201700145

Svobodová J, Smidova L, and Gvoždíková Javưrková V. 2019. Different incubation patterns affect selective antimicrobial properties of the egg interior: experimental evidence from eggs of precocial and altricial birds. Journal of Experimental Biology 222. 10.1242/jeb.201442

van Veelen HPJ, Salles JF, and Tieleman BI. 2017. Multi-level comparisons of cloacal, skin, feather and nest-associated microbiota suggest considerable influence of horizontal acquisition on the microbiota assembly of sympatric woodlarks and skylarks. Microbiome 5. 10.1186/s40168-017-0371-6

van Veelen HPJ, Salles JF, and Tieleman BI. 2018. Microbiome assembly of avian eggshells and their potential as transgenerational carriers of maternal microbiota. Isme Journal 12:1375-1388. 10.1038/s41396-018-0067-3

Valcu CM, Scheltema RA, Schweiggert RM, Valcu M, Teltscher K, Walther DM, Carle R and Kempenaers B. 2019. Life history shapes variation in egg composition in the blue tit Cyanistes caeruleus. Communications Biology 2.. 10.1038/s42003-018-0247-8

Voirol LRP, Weinhold A, Johnston PR, Fatouros NE, and Hilker M. 2020. Legacy of a Butterfly's Parental Microbiome in Offspring Performance. Applied and Environmental Microbiology 86. 10.1128/aem.00596-20

Wang C, Pors SE, Olsen RH, and Bojesen AM. 2018. Transmission and pathogenicity of Gallibacterium anatis and Escherichia coli in embryonated eggs. Veterinary Microbiology 217:76-81. 10.1016/j.vetmic.2018.03.005

Wang JM, and Beissinger SR. 2011. Partial incubation in birds: its occurrence, function, and quantification. Auk 128:454-466. 10.1525/auk.2011.10208

Wang JM, Firestone MK, and Beissinger SR. 2011. Microbial and environmental effects on avian egg viability: Do tropical mechanisms act in a temperate environment? Ecology 92:1137-1145.

Wellman-Labadie O, Picman J, and Hincke MT. 2008a. Antimicrobial activity of cuticle and outer eggshell protein extracts from three species of domestic birds. British Poultry Science 49:133-143. 10.1080/00071660802001722

Wellman-Labadie O, Picman J, and Hincke MT. 2008b. Comparative antibacterial activity of avian egg white protein extracts. British Poultry Science 49:125-132. $10.1080 / 00071660801938825$

Wu JP, and Acero-Lopez A. 2012. Ovotransferrin: Structure, bioactivities, and preparation. Food Research International 46:480-487. 10.1016/j.foodres.2011.07.012

Zhu F, Quu N, Sun H, Meng Y and Zhou Y. 2019. Integrated Proteomic and N-Glycoproteomic Analyses of Chicken Egg during Embryonic Development. Journal of Agricultural and

Peer) reviewing PDF | (2021:05:60948:2:1:NEW 2 Sep 2021) 
$775 \quad$ Food Chemistry 67:11675-11683. 10.1021/acs.jafc.9b05133. 


\section{Table $\mathbf{1}$ (on next page)}

Results of GLMM evaluating egg-white antimicrobial protein concentration (Avidin and Lysozyme) as a response of partial incubation, clutch covering with nest-lining feathers and their interactions.

Step-wise elimination of non-significant terms was used to select the best minimal adequate model (MAM). Predictors retained in the MAM after step-wise elimination of nonsignificant variables are in bold. Significance $(p)$ was assessed based on deviance change $\left(\chi^{2}\right)$ and corresponding degrees of freedom ( $\Delta$ d.f.). 


\begin{tabular}{llccc}
\hline Response & Predictor & $\Delta$ d.f. & $\chi^{2}$ & $\mathrm{p}$ \\
\hline \multirow{2}{*}{ Avidin } & Partial incubation & 1 & 3.281 & 0.070 \\
& Clutch covering & 1 & 0.000 & 0.987 \\
& Partial incubation x Clutch covering & 1 & 0.005 & 0.946 \\
\hline \multirow{2}{*}{ Lysozyme } & Partial Incubation & $\mathbf{1}$ & $\mathbf{2 5 . 7 1 6}$ & $<\mathbf{0 . 0 0 1}$ \\
& Clutch covering & 1 & 0.755 & 0.385 \\
& Partial incubation x Clutch covering & 1 & 0.951 & 0.330 \\
\hline
\end{tabular}

1

2

3

4

5

6 


\section{Table 2 (on next page)}

Results of GLMM evaluating variation in incidence and intensity of bacterial trans-shell penetration (BTSP).

Egg-white lysozyme and avidin concentrations, partial incubation, clutch covering with nestlining feathers, and their interactions were used as predictors. Predictors retained in the minimal adequate model after step-wise elimination of nonsignificant variables are in bold. Also shown are probability values $(p), \chi^{2}$ values and associated degrees of freedom ( $\Delta$ d.f.). 


\begin{tabular}{llccc}
\hline Response & Predictor & $\Delta$ d.f. & $\chi^{2}$ & $\mathrm{p}$ \\
\hline BTSP Incidence & Lysozyme & 1 & 1.619 & 0.203 \\
& Avidin & 1 & 0.001 & 0.981 \\
& Partial incubation & 1 & 0.052 & 0.820 \\
& Clutch covering & 1 & 0.052 & 0.820 \\
& Lysozyme x Partial incubation & 1 & 0.209 & 0.648 \\
& Lysozyme x Clutch covering & 1 & 0.488 & 0.485 \\
BTSP Intensity & 1 & 0.660 & 0.417 \\
& Avidin x Partial incubation & 1 & 0.328 & 0.567 \\
\cline { 2 - 5 } & Avidin x Clutch covering & 1 & 3.071 & 0.080 \\
& Incubation & 1 & 2.642 & 0.104 \\
& Avidin & 1 & 0.420 & 0.517 \\
& Lysozyme & 1 & 0.420 & 0.517 \\
& Clutch covering & 1 & 1.480 & 0.224 \\
& Lysozyme x Partial incubation & 1 & 0.772 & 0.379 \\
& Lysozyme x Clutch covering & 1 & 0.037 & 0.847 \\
& Avidin x Partial incubation & 1 & 0.305 & 0.581 \\
\hline
\end{tabular}

1

2

3 


\section{Table 3 (on next page)}

Results of GLMM evaluating variation in hatching success.

Egg-white lysozyme and avidin concentrations, partial incubation, clutch covering with nestlining feathers and their interactions were used as predictors. Predictors retained in the minimal adequate model after step-wise elimination of nonsignificant variables are in bold. Also shown are probability values $(p), \chi^{2}$ values and associated degrees of freedom ( $\Delta$ d.f.). 


\begin{tabular}{lccc}
\hline Predictor & $\Delta$ d.f. & $\chi^{2}$ & $\mathrm{p}$ \\
\hline Partial incubation & $\mathbf{1}$ & $\mathbf{8 . 7 9 6}$ & $\mathbf{0 . 0 0 3}$ \\
Lysozyme & 1 & 1.257 & 0.262 \\
Avidin & 1 & 1.575 & 0.209 \\
Clutch covering & 1 & 1.575 & 0.209 \\
Lysozyme x Partial incubation & 1 & 0.645 & 0.422 \\
Lysozyme x Clutch covering & 1 & 2.579 & 0.108 \\
Avidin x Partial incubation & 1 & 0.080 & 0.778 \\
Avidin x Clutch covering & 1 & 0.844 & 0.358 \\
\hline
\end{tabular}

1

2 


\section{Table 4 (on next page)}

Results of GLMM evaluating variation in morphometric parameters of hatchlings.

Variability in Residual body mass (i.e. body mass adjusted for egg volume), and Scaled BMI (condition index based on body mass and tarsus length) due to the effect of egg-white lysozyme and avidin concentrations and partial incubation was evaluated. Data were analysed using GLMMs assuming Gaussian distribution of residuals. Predictors retained in the minimal adequate model after step-wise elimination of nonsignificant variables are in bold. Also shown are probability values $(p)$, F-statistic values $(F)$ and associated degrees of freedom (d.f.). 


\begin{tabular}{llccc}
\hline Response & Predictor & d.f. & F & p \\
\hline Residual body mass & Partial incubation & $(1,26)$ & $\mathbf{2 3 . 9 8 2}$ & $\mathbf{0 . 0 0 0}$ \\
& Lysozyme & $(1,25)$ & 0.015 & 0.903 \\
& Avidin & $(1,24)$ & 0.007 & 0.935 \\
\hline Scaled BMI & Lysozyme & $(1,25)$ & $\mathbf{1 0 . 9 6 5}$ & $\mathbf{0 . 0 0 3}$ \\
& Partial incubation & $(1,25)$ & $\mathbf{7 . 2 2 7}$ & $\mathbf{0 . 0 1 3}$ \\
& Avidin & $(1,24)$ & 0.140 & 0.711 \\
\hline
\end{tabular}

1

2 
Figure 1

Variation of egg-white AMPs concentrations in Mallard (Anas platyrhynchos) eggs treated with partial incubation.

(A) Lysozyme and (B) Avidin, eggs treated with partial incubation (incub.), control unincubated eggs (unincub.). Also shown are GLMM-based probability values. 


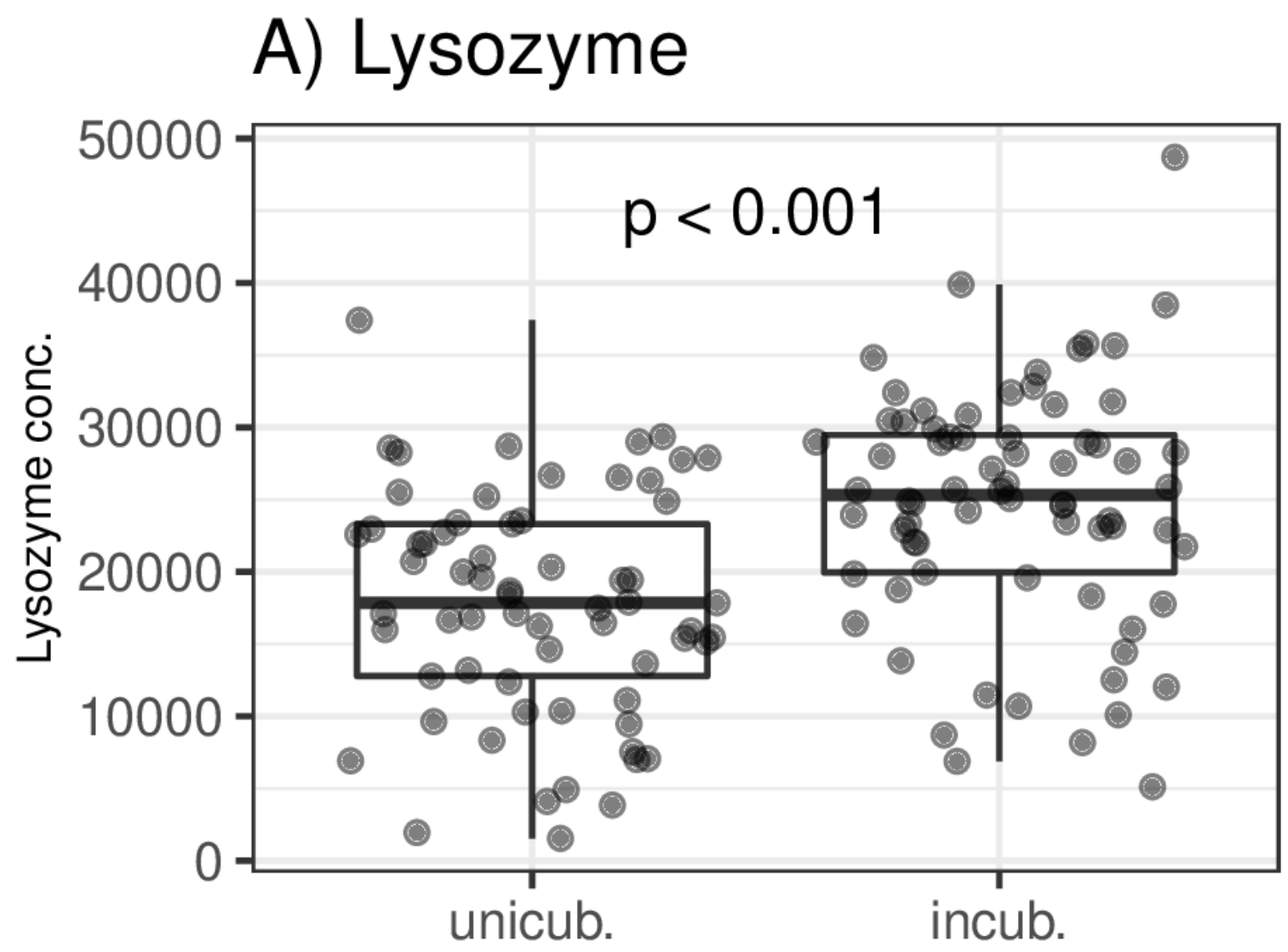

B) Avidin

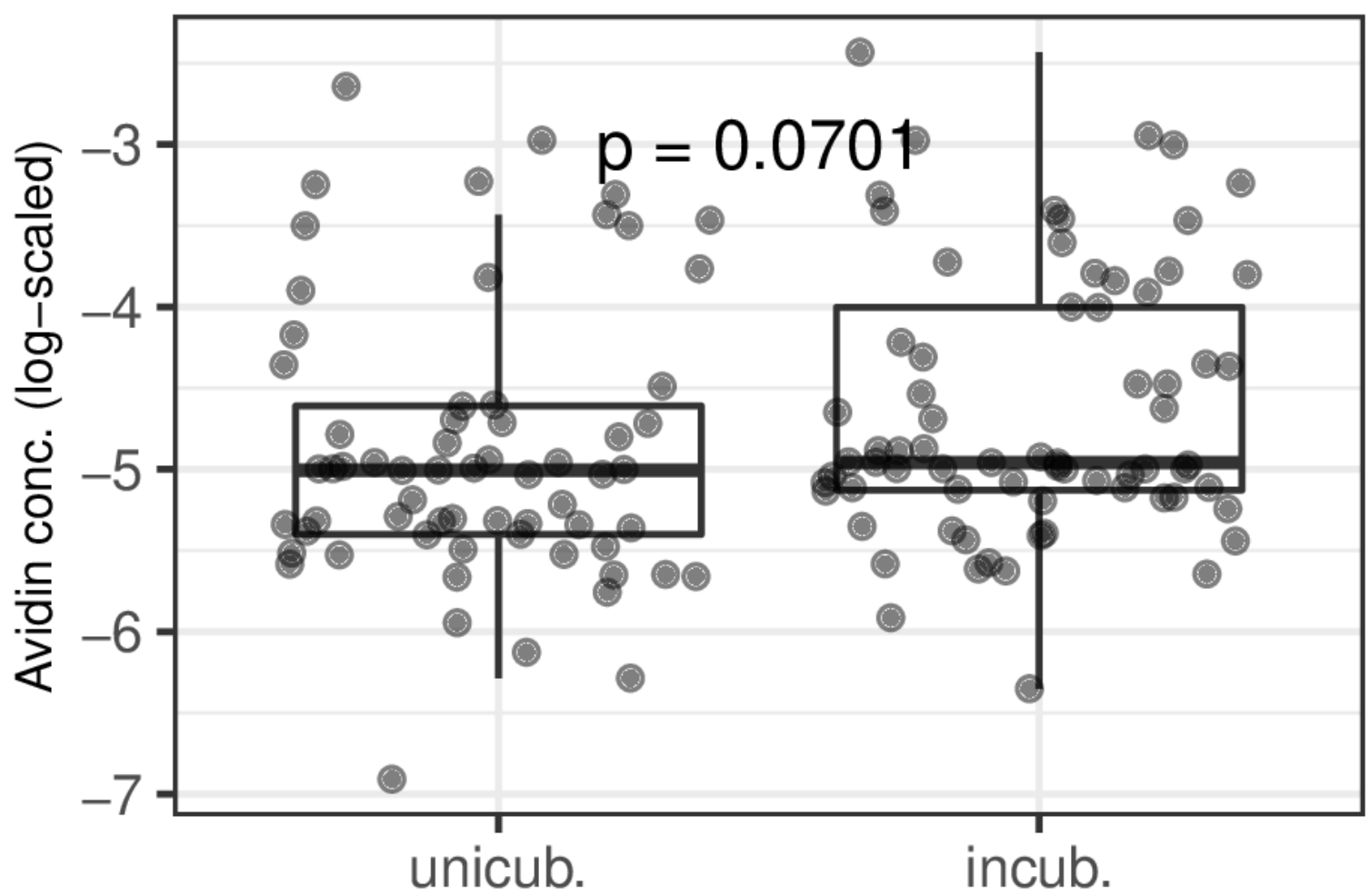


Figure 2

Effect of egg-white lysozyme concentrations on scaled BMI of Mallard (Anas platyrhynchos) hatchlings.

Regressions were adjusted for the effect of partial incubation treatment. Also shown are predictions and $95 \%$ confidence intervals. 


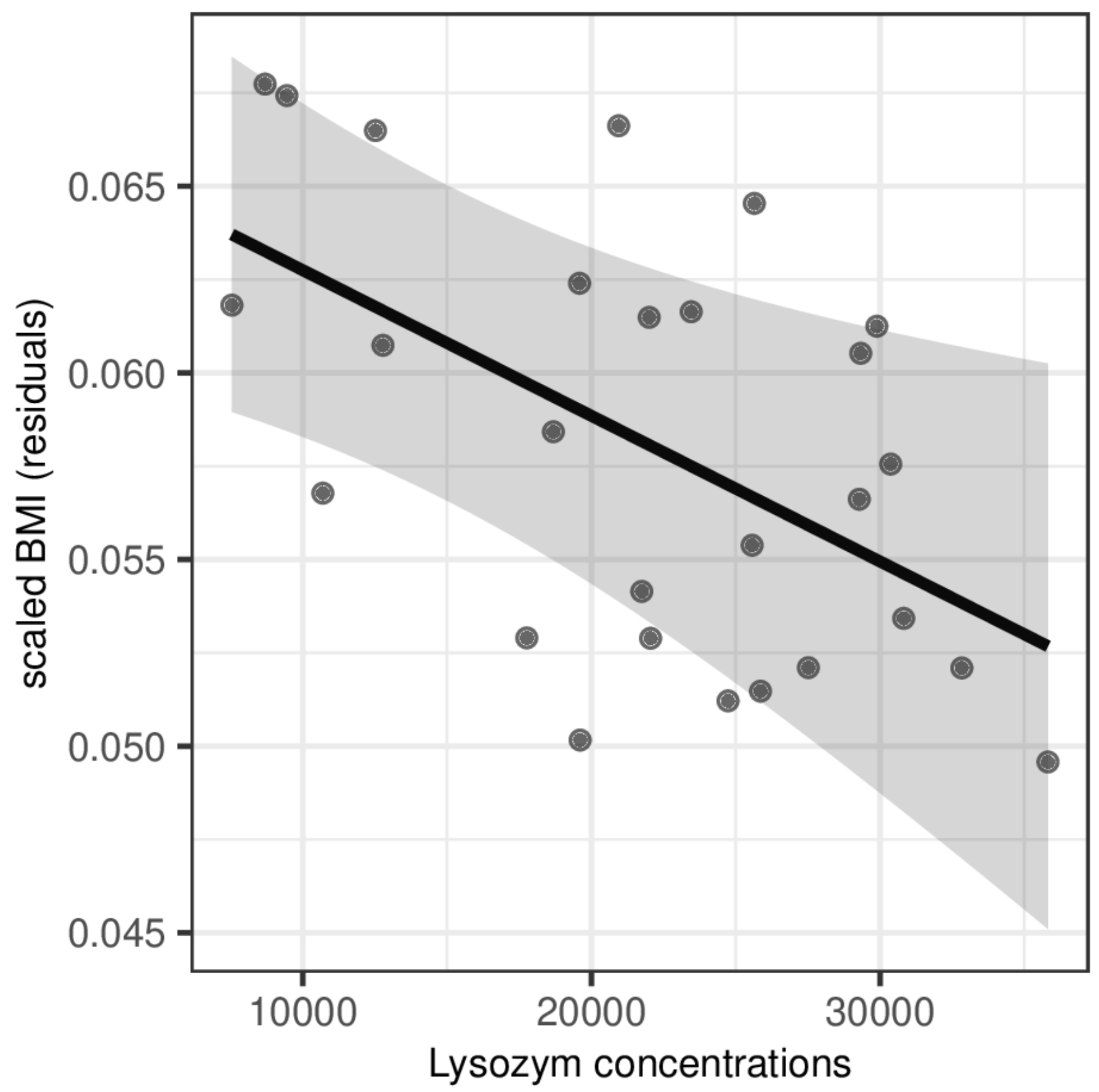

